\title{
Penerapan Aturan Asosiasi Algoritma Apriori Terhadap Penjualan Thai Tea Pada PT. Nyonya Besar Lestari
}

\author{
Normah $^{1,}$ Cristine Olivia ${ }^{2}$ \\ ${ }^{1}$ STMIK Nusa Mandiri, Teknik Informatika \\ Email: normah.nor@nusamandiri.ac.id \\ ${ }^{2}$ STMIK Nusa Mandiri, Sistem Informasi \\ Email: cristine1912@nusamandiri.ac.id
}

\begin{abstract}
With the existence of a cold drink business that has mushroomed, Thai Tea business owners need to think about finding new marketing strategies to increase sales, one of which is by using data mining processing so that the sales transaction data not only functions as a sales report, but also to find out the stock of beverage ingredients and buyer demand can be fulfilled, Determine which variants sell the most so that they can find variants with the highest and lowest interests. Apriori algorithm including the type of association rules in data mining. This study implements a priori algorithm for the purchase of beverages with a minimum support of $30 \%$ and a minimum of $60 \%$ confidence, and the results of the most widely sold Thai Tea variants are Thai Grass Jelly, Thai Taro milk, Thai Mango Yakult, Thai Milk Tea with support values $32.3 \%$ and confidence value $76.9 \%$.
\end{abstract}

Keywords: Data Mining, Apriori Algorithm, Thai Tea.

\section{PENDAHULUAN}

Seorang pebisnis khususnya dibidang penjualan akan mengumpulkan berbagai informasi untuk memperoleh keuntungan yang maksimal dan mencegah terjadinya kerugian. Dalam dunia bisnis seperti penjualan minuman, suatu toko penjualan minuman akan memperoleh data penjualan setiap terjadi transaksi. Data penjualan minuman yang diperoleh setiap harinya tidak akan ada artinya jika tidak diolah, hanya dibiarkan saja sebagai arsip.

Data Mining adalah proses mengekstraksi atau menggali pengetahuan dari data yang berjumlah besar. Data berskala besar memunculkan fenomena "data rich but information poor", dimana data yang berjumlah besar tidak diikuti dengan peningkatan informasi yang didapat dari data tersebut. Fenomena itu sering muncul pada sistem penjualan dipasar swalayan, dimana data transaksi terus bertambah setiap hari yang monoton. Hal ini dikarenakan kurangnya analisa terhadap kumpulan data tersebut (Gede, Putra, \& Bayupati, 2016).

Dengan keberadaan bisnis minuman dingin yang sudah menjamur, pemilik usaha Thai Tea perlu memikirkan untuk menerapkan strategi baru, salah satunya dengan menggunakan pengolahan data mining sehingga data transaksi penjualan tidak hanya berfungsi sebagai laporan penjualan, tetapi juga untuk mengetahui stok bahan minuman dan permintaan pembeli dapat terpenuhi, Menentukan varian paling banyak terjual sehingga dapat mengetahui varian dengan minat tertinggi dan terendah.

Algoritma Apriori termasuk jenis aturan asosiasi pada data mining. Algoritma Apriori adalah algoritma yang paling terkenal untuk menemukan pola frekuensi tinggi (Sianturi, 2018). Dimana data mining berusaha menemukan asosiasi atau keterkaitan data. Konsep ini bisa digunakan untuk tujuan baik bagi pedagang maupun pelanggan, seperti menempatkan barang-barang yang memiliki asosiasi kuat ditempat yang berdekatan sehingga pelanggan lebih mudah memudahkannya. (Suyanto, 2019).

\section{METODOLOGI PENELITIAN}

\section{Instrumen Penelitian}

Instrument penelitian adalah alat bantu yang dipilih dan digunakan oleh peneliti dalam kegiatannya mengumpulkan data agar kegiatan tersebut menjadi sistematis dan dipermudah olehnya. (Sofyan \& Budijono, 2016)

Instrument yang digunakan dalam penelitian ini adalah dengan melakukan pengamatan pada data penjualan dan melakukan wawancara untuk mendapatkan informasi. Gambar 1. Merupakan gambar tahapan pada penelitian ini: 


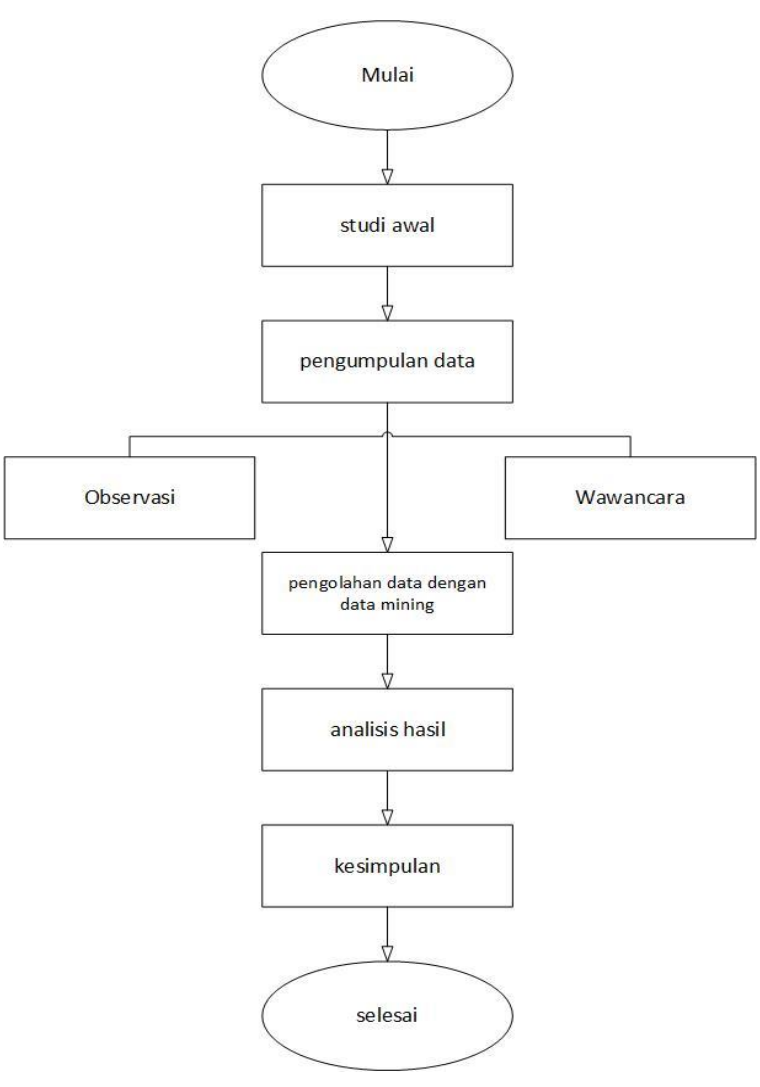

Gambar 1. Tahapan Penelitian

\section{Metode Analisis Data}

Data yang telah didapat dan dikumpulkan selama proses pengumpulan data kemudian akan masuk ketahap selanjutnya yaitu tahap analisis data. Metode analisis data ini yaitu dengan proses membedakan data sesuai jenisnya (Yanto \& Khoiriah, 2018). Dalam hal ini digunakan analisis apriori, sebagai berikut:

1. Analisis permasalahan pada toko Thai Tea Permasalahan akan dianalisa menggunakan metode algoritma apriori.

2. Mengolah data dengan menggunakan perhitungan algoritma apriori.

Berikut ini adalah beberapa tahapan yang dilakukan dalam perhitungan aloritma apriori:

a. Mencari varian yang paling banyak terjual Langkah pertama yaitu mencari nilai penjualan tertinggi dalam transaksi selama satu bulan.

b. Mengelompokkan beberapa varian yang paling banyak terjual.

c. Pembuatan Format Tabuar

Setelah nilai penjualan terbanyak disetiap bulannya sudah diketahui, maka akan dibuat form tabular agar dapat dianalisis dengan algoritma apriori.

d. Analisis Pola Frekuensi

Pada tahap ini peneliti mencari kombinasi antar item yang telah memenuhi syarat dari minimum nilai support (nilai penunjang) dalam basis data.
Support (A)

$$
\frac{\sum \text { Transaksi Mengandung A }}{\sum \text { Transaksi }} \times 100 \%
$$

Sementara nilai support dari 2 itemset diperoleh rumus:

$$
\begin{aligned}
& \text { Support }(\mathrm{A}, \mathrm{B})=\mathrm{P}(\mathrm{A} \cap \mathrm{B}) \\
& \text { Support }(\mathrm{A}, \mathrm{B}) \\
& \frac{\sum \text { Transaksi Mengandung A\&B }}{\sum \text { Transaksi }} \times 100 \%
\end{aligned}
$$

Yang mana nilai support A dan B diperoleh dari pembagian antara jumlah transaksi yang mengandung $\mathrm{A}$ dan $\mathrm{B}$ dengan total transaksi yang dikalikan dengan $100 \%$

\section{HASIL DAN PEMBAHASAN}

Data penjualan Thai Tea selama ini tidak dimanfaatkan dengan baik oleh perusahaan karena data penjualan selama ini tidak tersusun dengan baik. Data tersebut hanya disimpan sebagai arsip atau pembukuan perusahaan dan tidak diketahui manfaat dari data-data tersebut.

\section{Daftar Varian Thai Tea}

Berikut ini adalah daftar varian Thai Tea:

Tabel 1. Daftar Varian

\begin{tabular}{|c|l|}
\hline No & \multicolumn{1}{|c|}{ Varian } \\
\hline 1 & Thai Taro Milk \\
\hline 2 & Mango Creamy \\
\hline 3 & Thai Mango Yakult \\
\hline 4 & Thai Milk Tea \\
\hline 5 & Thai Cheese Tea \\
\hline 6 & Original Thai Tea \\
\hline 7 & Thai Green Tea \\
\hline 8 & Thai Chocolate \\
\hline 9 & Thai Matcha Latte \\
\hline 10 & Thai Coffe Chocolate \\
\hline 11 & Thai Coffe \\
\hline 12 & Thai Grass Jelly \\
\hline 13 & Thai Lemon Tea \\
\hline
\end{tabular}

\section{Pembentukan Itemset}

Penyelesaian berdasarkan data yang sudah disediakan pada tabel 2. Proses pembentukan $\mathrm{C}_{1}$ atau disebut dengan 1 itemset dengan jumlah minimum support $=30 \%$ dengan rumus sebagai berikut:

Support $(\mathrm{A})=\frac{\text { jumlah transaksi mengandung } \mathrm{A}}{\text { total ransaksi }} \times 100 \%$ 
Dari hasil perhitungan tersebut, dengan itemset minimum $30 \%$ hanya satu item yang tidak memenuhi standart yaitu Thai Lemon Tea dengan hasil support $25.8 \%$

\section{Kombinasi 2 Itemset}

Proses pembentukan $\mathrm{C}_{2}$ atau disebut 2 itemset dengan jumlah minimum support $=30 \%$ dapat diselesaikan dengan rumus berikut:

$$
\begin{gathered}
\text { Support }(\mathrm{A} \cdot \mathrm{B})=\mathrm{P}(\mathrm{A} \cap \mathrm{B}) \\
\text { Support }(\mathrm{A}, \mathrm{B})=\frac{\text { transaksi mengandung Adan }}{\text { total transaksi }} \times 100 \%
\end{gathered}
$$

Berikut adalah kombinasi item yang memenuhi standart minimum support $30 \%$.

\section{Tabel 2. Kombinasi 2 Itemset}

\begin{tabular}{|l|c|c|}
\hline \multicolumn{1}{|c|}{ Produk } & Qty & support \\
\hline thai taro milk, thai milk tea & $11 / 31$ & $35.5 \%$ \\
\hline thai taro milk, original thai tea & $14 / 31$ & $45.2 \%$ \\
\hline thai taro milk, thai green tea & $10 / 31$ & $32.3 \%$ \\
\hline thai taro milk, thai grass jelly & $10 / 31$ & $32.3 \%$ \\
\hline thai mango yakult, thai milk tea & $10 / 31$ & $32.3 \%$ \\
\hline original thai tea, thai taro milk & $20 / 31$ & $45.2 \%$ \\
\hline
\end{tabular}

\section{Pembentukan Aturan Asosiasi}

Setelah semua pola frekuensi tinggi ditemukan, barulah mencari aturan asosiasi yang memenuhi syarat minimum untuk confidence dengan rumus sebagai berikut:

Minimum confidence $=60 \%$

Nilai confidence dari aturan $\mathrm{A} \rightarrow \mathrm{B}$ diperoleh

$$
=\frac{\begin{array}{c}
\text { Confidence }=\mathrm{P}(\mathrm{A}, \mathrm{B}) \\
\text { transaksi mengandung } \mathrm{Adan}
\end{array}}{\text { total transaksi }} \times 100 \%
$$

\begin{tabular}{|c|c|c|c|}
\hline No & Aturan & \multicolumn{2}{|c|}{ Confidence } \\
\hline 1 & $\begin{array}{lrr}\text { Jika membeli } & \text { THAI } \\
\text { TARO MILK } & \text { maka } \\
\text { membeli } & \text { THAI } & \text { MILK } \\
\text { TEA } & & \\
\end{array}$ & $11 / 20$ & $55 \%$ \\
\hline 2 & $\begin{array}{lcr}\text { jika } & \text { membeli } & \text { THAI } \\
\text { MILK } & \text { TEA } & \text { maka } \\
\text { membeli } & \text { THAI } & \text { TARO } \\
\text { MILK } & & \\
\end{array}$ & $11 / 18$ & $61.1 \%$ \\
\hline 3 & $\begin{array}{l}\text { jika membeli } \text { THAI } \\
\text { TARO MILK maka } \\
\text { membeli ORIGINAL } \\
\text { THAI TEA }\end{array}$ & $14 / 20$ & $70 \%$ \\
\hline 4 & $\begin{array}{lr}\text { jika } & \text { membeli } \\
\text { ORIGINAL THAI TEA } \\
\text { maka membeli THAI }\end{array}$ & $14 / 20$ & $70 \%$ \\
\hline
\end{tabular}

\begin{tabular}{|c|c|c|c|}
\hline & TARO MILK & & \\
\hline 5 & $\begin{array}{l}\text { jika membeli } r \text { THAI } \\
\text { TARO MILK maka } \\
\text { membeli THAI GREEN } \\
\text { TEA }\end{array}$ & $10 / 20$ & $50 \%$ \\
\hline 6 & $\begin{array}{lrr}\text { jika membeli } & \text { THAI } \\
\text { GREEN } & \text { TEA } & \text { maka } \\
\text { membeli } & \text { THAI } & \text { TARO } \\
\text { MILK } & & \\
\end{array}$ & $10 / 14$ & $71.4 \%$ \\
\hline 7 & $\begin{array}{l}\text { jika membeli } \text { THAI } \\
\text { TARO MILK maka } \\
\text { membeli THAI GRASS } \\
\text { JELLY }\end{array}$ & $10 / 20$ & $50 \%$ \\
\hline 8 & 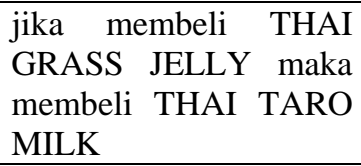 & $10 / 13$ & $76.9 \%$ \\
\hline 9 & $\begin{array}{l}\text { jika membeli } r \text { THAI } \\
\text { MANGO YAKULT } \\
\text { maka membeli THAI } \\
\text { MILK TEA }\end{array}$ & $10 / 13$ & $76.9 \%$ \\
\hline 10 & $\begin{array}{lr}\text { jika membeli } & \text { THAI } \\
\text { MILK TEA } & \text { maka } \\
\text { membeli } & \text { THAI } \\
\text { MANGO YAKULT }\end{array}$ & $10 / 18$ & $55.5 \%$ \\
\hline
\end{tabular}

Tabel 3. Aturan Asosiasi

\section{Implementasi Sistem}

Implementasi algoritma apriori ini menggunakan aplikasi Rapidminer untuk pengujian.

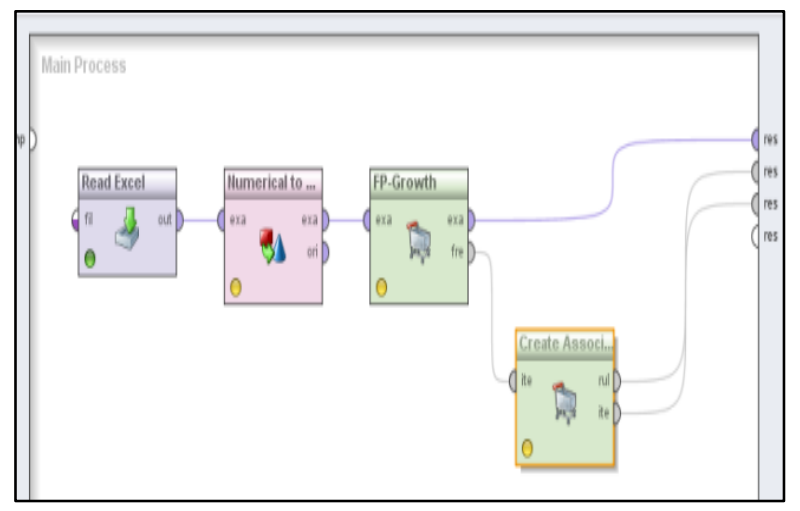

Gambar 2. Desain Model

Maka didapat hasil rule yang terbentuk menjadi 6 rule dari hasil RapidMiner 5.3 sebagai berikut : 


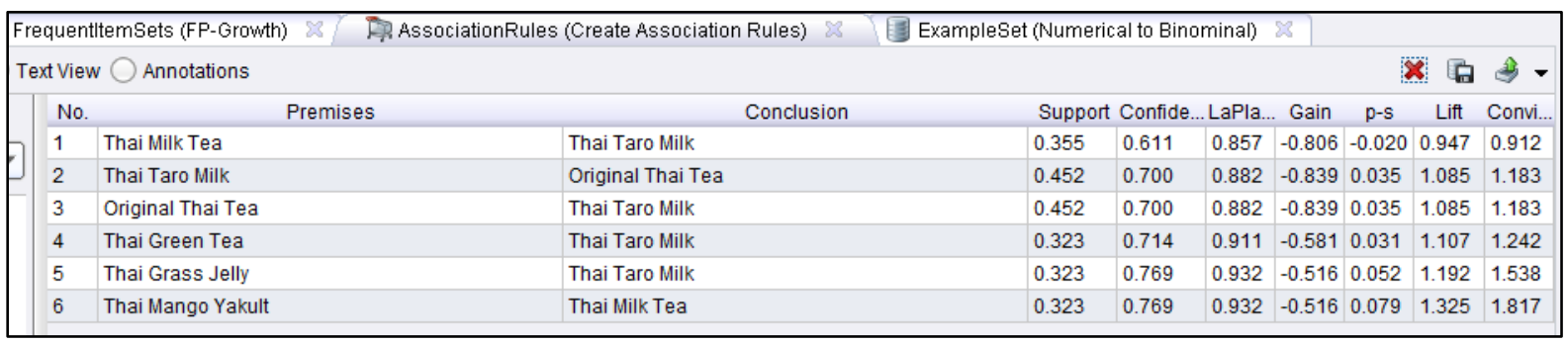

Gambar 3. Asosiasi Final

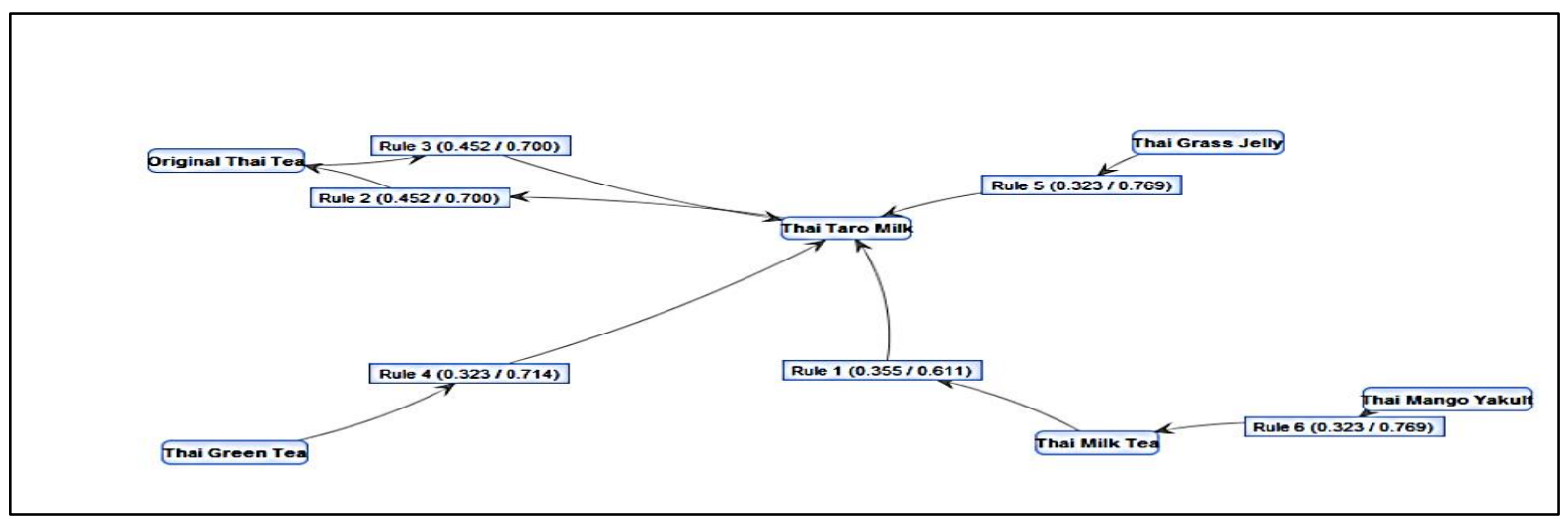

Gambar 4. Tampilan Grafik

Berdasarkan Assosiasi Final dan Graph View diatas, dapat disimpulkan ada 6 rule yaitu

1. Thai Milk Tea, Thai Taro Milk dengan nilai support 0.355 dan nilai confidence 0.611

2. Thai Taro Milk, Original Thai Tea dengan nilai support 0.452 dan nilai confidence 0.700

3. Original Thai Tea, Thai Taro Milk dengan nilai support 0.452 dan nilai confidence 0.700

4. Thai Green Tea, Thai Taro Milk dengan nilai support 0.323 dan nilai confidence 0.714

5. Thai Grass Jelly, Thai Taro Milk dengan nilai support 0.323 dan nilai confidence 0.769

6. Thai Mango Yakult, Thai Milk Tea dengan nilai support 0.323 dan nilai confidence 0.769

\section{KESIMPULAN}

Berdasarkan hasil penelitian menggunakan algoritma apriori dapat diambil kesimpulan varian Thai Tea yang paling banyak diminati dapat diketahui dengan melihat produk yang memenuhi minimal support $30 \%$ dan minimal confidence $60 \%$, barang yang paling banyak terjual adalah Thai Grass Jelly, Thai Taro milk, Thai Mango Yakult, Thai Milk Tea dengan nilai support $32.3 \%$ dan nilai confidence $76.9 \%$. Penerapan Algoritma Apriori pada dataset penjualan dapat membantu perusahaan dalam mengembangkan strategi pemasaran.

\section{REFERENSI}

Gede, I. K., Putra, D., \& Bayupati, I. P. A. (2016). MENEMUKAN FREQUENT ITEMSET DALAM. 15(2).
Sianturi, F. A. (2018). Penerapan Algoritma Apriori Untuk Penentuan Tingkat. 2(1), 50-57.

Sofyan, \& Budijono. (2016). Rancang Bangun Perangkat Pembelajaran Praktikum Instrumentasi Dan Kendali Standar Kompetensi Memahami Sistem Mekatronika Dalam Peralatan Kontrol Otomatis Bagi Mahasiswa Teknik Mesin UNESA.

Suyanto. (2019). Data Mining Untuk Klasifikasi Dan Klasterisasi Data.

Yanto, R., \& Khoiriah, R. (2018). Implementasi Data Mining Dengan Metode Algoritma Apriori Dalam Menentukan Pola Pembelian Obat. Creative Information Technology Journal, $2(2), \quad 102$. Https://Doi.Org/10.24076/Citec.2015v2i2.41

\section{PROFIL PENULIS}

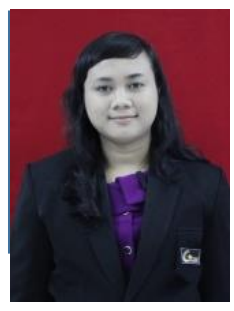

Normah, Memperoleh gelar Master Komputer (M. Kom), Jurusan Magister Ilmu Komputer Program Pasca Sarjana STMIK Nusa Mandiri. Saat ini menjadi dosen di STMIK Nusa Mandiri (S1) Jakarta.

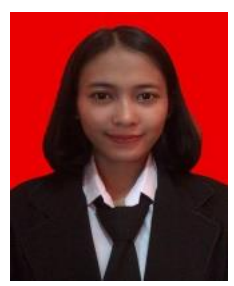

Cristine Olivia, Penulis kedua. Memperoleh gelar Sarjana Komputer (S.Kom), Jurusan Sistem Informasi, STMIK Nusa Mandiri. 